\title{
PRENSA PERIODICA ESPAÑOLISTA EN MÉXICO
}

\author{
Lydia Elizalde ${ }^{1}$
}

RESUMO: No final do século XIX, com a estabilidade introduzida no início dos anos do Porfiriato, houve um maior afluxo de migração para o México, evidente no crescimento da presença espanhola em certos ambientes econômicos do país. Dentro do grupo de jornais das colônias de estrangeiros foram publicadas, destacase o trabalho de editores e escritores como empreendedores culturais. Enfatizado neste ensaio a fundação e consolidação do jornal El Correo Espanhol publicada na Cidade do México durante os primeiros dez anos de sua fundação, de 1889 a 1898.

PALAVRAS-CHAVE: Migrações espanholas. Jornalismo finisecular. El Correo Espanhol.

RESUMEN: A finales de siglo XIX, con la estabilidad instaurada en los primeros años del porfiriato, hubo una mayor afluencia de migraciones a México, evidente en el crecimiento de la presencia española en ciertos entornos económicos de la nación. Dentro del conjunto de los periódicos de las colonias de extranjeros que se

1 Doctora en Historia del Arte; profesora-investigadora en la Facultad de Artes, UAEM; pertenece al Sistema Nacional de Investigadores de Conacyt. Autora de artículos sobre semiótica del arte y la gráfica, de teorías y crítica del arte contemporáneo y del desarrollo editorial en México. Destacan sus publicaciones autorales: Diseño en la Revista Universidad de México (2009), Plástica contemporánea en publicaciones (2014), El Correo Español, aportes a la prensa periódica en México (1889-1898), (2016). Coordinadora de los libros Revistas culturales latinoamericanas 1920-1960 (2008), Revistas culturales latinoamericanas 1960-2008, (2010), Intertextualidades. Teorías y critica del arte y la literatura, (2014); co-coordinadora del texto Imaginarios del grotesco, teoría y crítica; y de la revista deSignis \# 21 Semióticas gráficas (2013). Desde 2005 a la fecha ha sido directora y editora de la revista Inventio, y responsable del programa de publicaciones de la UAEM. Correo-e: Iydiaelizalde@uaem.mx 
publicaron, destaca el trabajo de editores y escritores españoles como empresarios culturales. Enfatizo en este ensayo la fundación y consolidación del periódico El Correo Español publicado en la Ciudad de México durante los diez primeros años de su fundación de 1889-1898.

PALABRAS CLAVE: Migraciones españolas. Periodismo finisecular. El Correo Español.

ABSTRACT: At the end of the nineteenth century, with the stability introduced in the early Porfiriato years, there was a greater influx of migration to Mexico, evident in the growth of the Spanish presence in certain economic environments of the country. Among the published foreign colonies newspapers, the work of editors and writers as cultural entrepreneurs are highlighted. Emphasized in this essay is the founding and consolidation of the Spanish newspaper El Correo Español published in Mexico City during the first ten years of its founding since 1889 until 1898.

KEYWORDS: Spanish migrations; Finisecular journalism, El Correo Español.

\section{Introducción}

El auge de la prensa fue uno de los emblemas de la modernidad en Europa y América. Las empresas periodísticas, en el siglo XIX, estuvieron ligadas al crecimiento de talleres de impresión. La edición de publicaciones periódicas aseguraba el trabajo diario a las imprentas, de manera que la edición de periódicos era un complemento al de la producción de libros (SÁNCHEZ ILLÁN, 2001, p. 397)².

2 Este artículo se fundamenta y retoma algunos fragmentos del estudio realizado por la autora, titulado El Correo Español. Aportes a la prensa periódica en México (1889-1898). 
Con la implementación de los procedimientos técnicos, la prensa se convirtió en un eficaz instrumento de la divulgación de la información y de influencia en la opinión pública. Esto fue posible por el desarrollo tecnológico, elemento crucial para el nuevo periodismo. En un periodo de tiempo relativamente corto, de 18601900, se desarrollaron tecnologías para mejorar las posibilidades comunicativas: el telégrafo, el teléfono, la prensa rotativa de varios cilindros que se sumó a las eficientes técnicas de impresión con máquinas planas y a las técnicas del huecograbado para la reproducción de clichés fotográficos (SÁNCHEZ ILLÁN, p. 401).

La evolución de la difusión de la información a través de la prensa, que se desarrolló en Europa, se replicó simultáneamente en América. Este periodismo siguió algunas de sus premisas, incluyendo el enfoque editorial, la clasificación de los hechos y su compilación en las diferentes secciones: noticias políticas nacionales y del extranjero; dio énfasis a las noticias culturales, añadió la reseña de opinión, la crónica y continuó la publicación de obras literarias. Modificó su tamaño y aumentó las tiradas; sobresalió por el uso de un lenguaje sencillo, claro, directo y próximo a los lectores. Sus alcances fueron evidentes en las transformaciones que se produjeron en la economía, la política, la educación y la vida cotidiana.

En el siglo XIX, el periódico fue el principal medio de comunicación, considerado el cuarto poder ideológico para conformar la opinión pública. Desde este periodo fue evidente la estrecha relación entre la clase política y el periodismo. En la prensa aparecían las orientaciones políticas y funcionaba mayormente como medio de difusión del gobierno en el poder, pero también divulgaba ideas contrapuestas. En cuanto a la propagación de la información, la prensa contribuyó al desarrollo de la educación (THÉRENTY, 2012).

\section{La prensa en el porfiriato}

Sobre las condiciones que favorecieron el desarrollo de la prensa en México en el siglo XIX, explica la historiadora Laurence 
Coudart, que el periodismo surge como medio privilegiado para una élite letrada, hasta que surge el pueblo en el escenario político, el pueblo nación bajo la "legitimidad de la nueva organización política y económica: el liberalismo, cuyo primer postulado es la libertad de pensamiento, de expresión y de imprenta" (COUDART, p. 160).

Y detalla:

En el México independiente, el carácter doctrinario y partidista de la prensa se conjuga con la persistencia de la retórica ilustrada. Desde los años 1820, y de manera durable a lo largo del siglo, los periodistas se definen esencialmente como guías, vanguardias o centinelas, que velan por el bien común de la nación en construcción y cuya función consiste en formar y convencer a la naciente 'opinión pública', muy lejos de constituir un conjunto singular y homogéneo. Se perfila así un voluntarismo cierto, integrador si bien partidista, una batalla de largo aliento característica de las sociedades heterogéneas. (COUDART, p. 157).

Durante el periodo de 1876 a 1911, Porfirio Díaz ocupó la presidencia del país, con la excepción de los cuatro años en los que gobernó Manuel González, de 1880 a 1884. El largo periodo de gobierno de Díaz resultó crucial para la consolidación del estado nación pues "ganó en la unificación del país, en la creación de una identidad nacional y en la defensa de la soberanía" (SPECKMAN, 2013, p. 207-208); el país logró alcanzar la estabilidad política y se registró un crecimiento económico, a la par de un evidente rezago de beneficios sociales para las mayorías.

El panorama del desarrollo político del gobierno de Porfirio Díaz refleja la transición de sus dos etapas: el primer porfiriato abarcó de 1877 a 1890, y su principal objetivo fue la conciliación y la unificación del país. Díaz pactó con diversas fuerzas políticas logrando incorporar a su gabinete sectores liberales, conservadores e incluso imperialistas (SPECKMAN, 2013, p. 193). En el periodo de 1890 a 1908 se abandonó el ánimo conciliatorio y se dio paso a un acentuado centralismo (SPECKMAN, 2013, 
p. 207), actitud que provocó un descontento que culminó con la revuelta armada que derrocó a Díaz y a su régimen en 1910.

El gobierno de Díaz estaba sujeto a un escrutinio desde la prensa liberal debido a las acciones dictatoriales en beneficio de grupos minoritarios y represivos contra una mayoría, pobre y sin educación. Durante estas tres décadas se pueden ver que el gobierno de Díaz subvencionó los periódicos oficiales y dio prebendas a los diarios que lo apoyaban; para los diarios de oposición hubo operaciones represivas: encarcelamientos, sanciones monetarias, sentencias de confiscación de prensas y útiles de trabajo (RUIZ CASTAÑEDA, 1980, p. 231).

La prensa nacional que se desarrolló durante el gobierno de Díaz presentó dos líneas importantes: por un lado, un periodismo que se adaptaba a las políticas gubernamentales y, por el otro, un periodismo de oposición vigilante, combativo y crítico (RUIZ CASTAÑEDA, 1980, p. 229).

En los primeros años del porfiriato hubo una coexistencia relativa y pacífica de tres ideologías: la conservadora, la liberal y la positivista. En la última década del gobierno de Díaz, el positivismo fue cobrando más fuerza y constituyó el apoyo al régimen desde su empirismo siguiendo la consigna "Paz, Orden y Progreso" (CLARK; FLORES, 2006, VIII) ${ }^{3}$.

El periodismo nacional cobró un gran impulso y se consolidó como un eficaz instrumento de opinión. Pablo Piccato trata el florecimiento de la prensa crítica:

Leer los periódicos publicados entre 1867 y 1876, sobre todo en la ciudad de México, revela una pléyade de hombres valientes que se enfrentaban al gobierno entre sí. Las leyes de prensa aprobadas en

3 El acercamiento a los estudios de la prensa del porfiriato realizados actualmente por historiadores y literatos, han abierto la inclusión de perspectivas desde otras disciplinas, desde la ciencia política, las ciencias de la comunicación, los estudios literarios, enriqueciendo aún más el panorama del desarrollo de periodismo. Destaco los estudios realizados por Laurence Coudart, Pablo Piccato; y los de especialistas en estudios literarios del XIX, Belem Clark de Lara, Elisa Speckman, entre otros investigadores citados en este ensayo. 
1861 y 1868 bajo la inspiración de Guillermo Prieto protegieron la libertad de expresión mediante los jurados de prensa, una institución que tendían a absolver a los periodistas acusados de difamación o calumnias. (PICCATO, p. 6).

A los grupos de periodistas nacionales se sumaron los representantes del capital extranjero para preservar la estabilidad de sus inversiones en México. Esta prensa estaba sostenida por las colonias extranjeras que tenían invertidos grandes capitales e interesados en la conservación de la paz y el progreso que supuestamente proporcionaría la continuación del general Díaz en la presidencia (RUIZ CASTAÑEDA, 1980, p. 229).

La injerencia de la colonia extranjera en los trabajos reeleccionistas del gobierno de Porfirio Díaz permitió el desarrollo de periódicos editados por sus representantes en México y son estos los que tuvieron una duración más prolongada en la convulsionada época de 1880 a 1910 , en que se editaban y desaparecían tanto los periódicos conservadores como los liberales que oponían a la reelección del presidente Díaz (RUIZ CASTAÑEDA; REED TORRES; CORDERO Y TORRES, p. 237).

Es común considerar al régimen de Porfirio Díaz como uno de los más proclives a favorecer los intereses extranjeros de la historia mexicana (BUCHENAU, p. 1996). Sin embargo, señala el historiador que esta visión tenía dos caras:

Por un lado, los porfiristas, discípulos de las filosofías modernizadoras occidentales en boga durante el siglo XIX, creyeron que al estrechar los vínculos con las pujantes nacionales industriales del norte desarrollarían un Estado mexicano fuerte. Pondrían fin así a la inestabilidad política y a las invasiones extranjeras de las décadas anteriores. Por esta razón, compartida por muchos de sus contemporáneos en Latinoamérica, acordaron conceder importantes privilegios a los propietarios extranjeros. (BUCHENAU, 1996).

Dentro del conjunto de los periódicos de las colonias de extranjeros en el país, destacan los diarios españoles, objeto 
de este ensayo, le siguen los americanos, los franceses y los alemanes que se editaron a la par de edición de El Correo Español durante la última década del XIX.

El modelo de la prensa norteamericana generó en el país un periodismo moderno de gran circulación, fundamentalmente noticioso, ágil, para ofrecer a los lectores más información nacional e internacional que se adquiría a través de las agencias noticiosas como miembros de La Prensa Asociada fundada en Estados Unidos en 1848.

Entre las reseñas sobre la prensa en la última década del siglo XIX en México destacó el trabajo realizado por el pedagogo y ensayista de origen suizo Enrique Rébsamen. En 1891, describe en la revista México Intelectual ${ }^{4}$ que en el país se editaban 328 publicaciones periódicas, de las cuales setenta y siete surgían en la Ciudad de México, incluyendo los órganos de las colonias extranjeras en México, redactados en inglés, francés y alemá" (BOPP, p. 567).

En cuanto a su edición, los periódicos nacionales y los extranjeros presentaban similitudes conceptuales y formales. Lise Andries en Transferencias culturales en la prensa cita las aseveraciones de Alain Vaillant sobre la evolución de los diarios europeos que "esta evolución siguió las mismas etapas a pesar de las diferencias geográficas, sociales, políticas: el paso de una prensa de opinión a una prensa de información" (ANDRIES, 2011). Detalla que no solo los modelos editoriales y tipográficos eran casi los mismos, sino que estos cambios fueron simultáneos en Europa y de un continente a otro. Se importaban las tecnologías de producción y también las formas gráficas editoriales (ANDRIES, 2011).

El conocimiento de las distintas manifestaciones de la cultura norteamericana, francesa, alemana y española, difundida a través de la información en los diarios que se editaban en el ambiente

4 Revista cultural y pedagógica que se publicó inicialmente en Jalapa de 1889 a 1894, y después en México, D.F. hasta 1904. Los redactores propietarios fueron Enrique C. Rébsamen, Manuel E. Fuentes y Betancourt y Hugo Topf. 
mexicano de finales del siglo XIX, mostraba una apertura y el interés hacia diversos contenidos informativos, ideológicos y gráficos provenientes de esos países. Estas representaciones fueron determinantes en la difusión de los modelos extranjeros, que influyeron en la construcción del imaginario cultural nacional, sin dejar de mencionar que estos medios de información estaban, inicialmente, dirigidos a las élites de la sociedad.

\section{Periodistas españoles en México}

En la compilación histórica sobre españoles en el periodismo mexicano, Pablo Mora destaca que la presencia de periodistas peninsulares en México fue notable desde 1836, "una fecha simbólica porque fue cuando se reiniciaron las relaciones entre ambas naciones después de que México se proclamara independiente en 1821" (MORA, 2008, p. 15) y así lo detalla:

[...] en la tradición periodística en el XIX mostraba la difusión empresarial, la literaria y un enfoque editorial complejo, que buscaba establecer lazos culturales entre las dos naciones. La visión empresarial para desarrollar proyectos periodísticos basados en la apertura de ley de imprenta a raíz de la Independencia y en la colaboración con editores mexicanos. En una primera etapa, la participación de estos primeros periodistas e impresores españoles fue en la edición de periódicos y revistas. (MORA, 2008, p. 16).

Durante el periodo de la República Restaurada (1867-1876) se establecieron en México periodistas y editores españoles quienes contribuyeron al desarrollo del periodismo y se sumaron al trabajo iniciado por Anselmo de la Portilla, entre ellos destacan: Adolfo Llanos y Alcaraz, Niceto de Zamacois, Telésforo García, Enrique de Olavarría y Ferrari, Santiago Bellescá y J. de Elizalde (MORA, 2008, p. 16). Desde las páginas de los diarios que dirigieron, refiere el investigador: 
[...] colaboraron en la consolidación del fomento a la lectura, la instrucción de la población, la difusión de la información, al mismo tiempo que buscaron satisfacer las demandas de lectores de la comunidad española en México. Con ellos se conforma un periodismo más específico [...] y el establecimiento de una nueva recepción cultural editorial en términos historiográficos, literarios y de información. (MORA, 2008, p. 16).

La revisión que coordinan Mora y Miquel: "ha permito identificar una tradición periodística, empresarial, literaria y editorial compleja que se plantea como una forma de establecer lazos culturales en las dos naciones" (MORA, 2008, p. 15). Destaco la continuidad de los objetivos de los periódicos españoles que se editaron en México durante el porfiriato.

Se destaca en esta revisión el aporte, a mediados del siglo XIX, la presencia de Rafael de Rafael y de Anselmo de la Portilla, quienes fortalecieron los talleres de impresión con la edición de publicaciones periódicas. Anselmo de la Portilla, impulsor de varias empresas periodísticas, fundó los diarios El Español (1851), La Razón de México (1864), El Eco de Europa (1862) y La Iberia (1867-1876) diario a cargo de Adolfo Llanos y Alcaraz orientado a una presencia española más cohesionada a partir de la fundación del Casino Español de México (1863) (PI-SUÑER, 2008, p. 65); La Colonia Española (1873-1879) y apoyado por la Sociedad de Beneficencia Española (VIEYRA, 2010); La Voz de España (1879-1880) dirigido por Enrique Muñiz y José Barbier (editado en la imprenta de Filomeno Mata, con tipografía de José Correa); El Centinela Español (1879-1883) bisemanario político y literario fundado por Telésforo García, director propietario responsable; le siguió en su dirección Ramón Elices Montes. El Pabellón Español (1883-1890), periódico

5 La Sociedad de Beneficencia Española fue fundada como el 9 de octubre de 1842 por Francisco Preto y Neto, primer Cónsul General de España en México, para socorrer a los españoles necesitados; este es el antecedente del actual Hospital Español. 
dedicado exclusivamente a la defensa de los intereses de los españoles, fundado por Ramón Elices Montes y dirigido por José G. de Velasco. Centro esta revisión con el periódico El Correo Español (1889-1914), fundado y dirigido por Fernando Luis J. de Elizalde de 1889-1898 (MORA, 2008, p. 15); después de esta fecha la propiedad del diario pasó a diferentes editores españoles hasta su cierre en 1914 (ELIZALDE, 2008, p. 364). En 1894, J. de Elizalde fundó el periódico La Nación, dirigido a un público amplio; de 1906-1911 se publicó La Iberia, diario formado por un grupo de españoles agrupados en la Cámara de Comercio Española y que llevaba el lema "diario de la mañana".

\section{Migraciones españolas a finales del siglo XIX}

Describe la historiadora Clara E. Lida, en los estudios que ha realizado sobre los españoles residentes en México después de la independencia, que existen "numerosas lagunas sobre el asentamiento migratorio peninsular" (LIDA, 2006, p. 613). Se refiere concretamente a la población española que llegó a México entre la independencia y el inicio del porfiriato (1821-1876) y cuyos permanencias las hicieron mayoritariamente en las ciudades de Puebla y México (LIDA, 2006, p. 616).

Sobre los perfiles poblacionales, en los últimos años del siglo XIX, que se obtuvieron del Registro Nacional de Extranjeros (RNE), de los censos nacionales y otras series cuantitativas, señala Lida: "los datos son cualitativamente desiguales y deben ser tomados con cautela" (LIDA, 2006, p. 616). Ya que, como describe la historiadora, "las entradas y salidas del país que se registraban se hacían de manera independiente y estos registros individuales se pudieron duplicar o multiplicar" (LIDA, 2006, p. 616), refiere Lida:

6 Se suman los detallados estudios sobre los españoles en el XIX en México realizados por Antonia Pi-Suñer y Dolores Pla Brugat, entre otros estudiosos de la migración peninsular. 
Además, en México, 'en el siglo XIX, en particular, antes de promulgarse la Constitución de 1857, el asunto de la nacionalidad fue un problema jurídico fundamental, ya que las fronteras entre ser peninsular o mexicano no siempre fueron claras, y menos aún si se era criollo'. (LIDA, 2006, p. 618).

Continúa la historiadora:

En comparación con otras naciones latinoamericanas, la inmigración española a México no tuvo un peso cuantitativo importante dentro del caudal migratorio peninsular, ni tampoco incidió de modo importante en los índices de población en México. La importancia del fenómeno migratorio en este país no fue cuantitativo sino cualitativo. (LIDA, 2006, p. 621).

Durante el primer medio siglo de vida independiente, las condiciones políticas y las perspectivas económicas no fueron suficientemente atractivas para migraciones, sino quienes llegaban a México lo hicieron retomando las redes y cadenas migratorias que permanecían desde la época colonial. (LIDA, 2006, p. 620).

A finales del siglo XIX, debido a la estabilidad instaurada en los primeros años del porfiriato, hubo una mayor afluencia de peninsulares a México, que se tradujo en la creciente presencia española en ciertos ámbitos de la economía y en diferentes regiones del país. (LIDA, 2006, p. 620).

La historiadora señala que la información sobre las actividades económicas de los españoles en México se concentró en aquellos que pertenecían a las élites (LIDA, 1993, p. 205) y presenta los porcentajes de la población de españoles en el territorio mexicano: la población total en el país, en el registro correspondiente al año 1900, era de 13, 601, 272; y la población de españoles correspondía a 16, 280, únicamente un $0,11 \%$, de los cuales el $82,16 \%$ eran hombres ${ }^{7}$.

7 Quinto censo de población, resumen general (1930). Datos tomados de Clara E. Lida (1993, p. 205). 
Sobre las tipologías de los migrantes, detalla la historiadora:

Durante este periodo la migración es libre, dejada a la voluntad individual, a partir de la capacidad de un inmigrante de establecer vínculos propios con otros inmigrantes residentes en un país o integrarse a las redes comunales o familiares existentes. De manera que la inmigración libre es más heterogénea y fragmentaria en sus fuentes. (LIDA, 2006, p. 206).

\section{Continúa,}

Esto explicaría también la formación de fuertes colectividades españolas, a su vez subdivididas según regiones emigratorias con marcadas características geográfico-culturales. [...] Las publicaciones de las cámaras de comercio y las industriales españolas, relevan el mundo político y social de los empresarios peninsulares en las grandes ciudades mexicanas, como Puebla, Veracruz, Monterrey y, sobre todo, la Ciudad de México en este era libre en el país, de carácter urbano, con el predominio de comerciantes y propietarios y negociantes acomodados; 'toda una pequeña burguesía esparcida por las ciudades más activas del país'. (LIDA, 2006, p. 207).

Enfatiza la especialista acerca del carácter de empresarios culturales, tanto de los editores como de los escritores españoles radicados en México durante las últimas décadas del siglo XIX; por su parte, Lilia Vieyra reseña que la actividad periodística de los ibéricos en México permitió el desarrollo de un movimiento cultural paralelo al que se vivía en España (VIEYRA, p. 2007) ${ }^{8}$.

8 "La emigración del norte de España a México fue un aspecto que se desarrolló en las postrimerías del siglo XVIII, la mayoría era originaria de la región cantábrica: Asturias, Navarra y las montañas de Burgos. Antonia Pi-Suñer también asienta que la zona norte de España destacó como una región caracterizada por su emigración a América. Actualmente, los académicos santanderinos han valorado este aspecto desarrollando proyectos de investigación en donde se han integrado los estudios de historiadores mexicanos que dan cuenta del desarrollo regional y nacional de la República Mexicana a través de los esfuerzos de productores y comerciantes de Cantabria". (VIEYRA, 2012, p. 5). 
Aimer Granados, cita a Tomás Pérez Vejo sobre "la privilegiada posición económica de los españoles en México". "De españoles o españolizados son los periódicos siguientes: El Correo Español, El Correo de España, El Nacional, El Universal, El Tiempo, El Popular, El Liberal y El Frégoli” (GRANADOS, 2010, p. 78).

\section{La publicación de El Correo Español}

El antecedente del enfoque periodístico de El Correo Español se inicia con la publicación El Centinela Español (1879-1883) bisemanario político y literario fundado por Telésforo García, director propietario responsable; a este le siguió el periódico El Pabellón Español (1883-1890), diario fundado por Ramón Elices Montes. En su libro Cuatro años en México: memorias de un periodista españo/ ${ }^{9}$, relata que en 1879 había publicado en Madrid varios artículos referentes a México en la Unión y La Correspondencia Militar. A finales de ese año emprendió su viaje a México, en enero de 1880 desembarcó en Veracruz y se trasladó a la Ciudad de México, donde se dirigió al empresario y escritor español Telésforo García para formar parte de la redacción de El Centinela Español (1879-1883) (ELICES, 1879).

Después de su colaboración en el diario, por donación de su fundador, este pasó a su propiedad, y se hizo cargo de su dirección y publicación trimestral de 1881 hasta su cierre en 1883 , año en el que fundó el diario El Pabellón Español, periódico que llevaba el lema: "exclusivamente dedicado a la defensa de los intereses españoles", dirigido, en diferentes peridos, por José Román Leal, José Gándara de Velasco, Diego Bustillo, Lorenzo A. Mirante, y publicado en la imprenta del mismo diario. En 1884, el director se despidió de los lectores desde las columnas del diario y en sus funciones le siguieron otros miembros de la junta directiva de la publicación.

9 Obra publicada en 1885 con prólogo de Emilio Castelar, político, historiador, periodista y escritor; presidente del Poder Ejecutivo de la Primera República Española, de 1873 y 1874. 
Otro editor que se sumó a este enfoque españolista fue Fernando Luis Juliet de Elizalde, originario de la provincia de Álava, País Vasco, quien realizó estudios de jurisprudencia en la Universidad de Zaragoza. A mediados de la década de 1880 emigró a México y se incluye, por el periodo de su internación al país, en el grupo inmigrantes privilegiados que llegaron con una profesión y recursos económicos para establecer una empresa, en su caso, una sociedad editorial. Se suma su práctica como escritor de reseñas jurídicas y textos poéticos en diferentes diarios españoles y revistas de cultura.

Las razones de J. de Elizalde de emigrar a México, además de personales, seguramente estaban relacionadas con la estabilidad política en México, durante el primer periodo de gobierno de Porfirio Díaz y la apertura para invertir en el país. Se suman a éstas, la comunicación que tenían los españoles de ambos países para lograr metas comunes a favor de preservar la cultura española entre sus nacionales inmigrantes, así como patrocinar y cuidar los intereses comerciales de España en México.

A su llegada a México se relacionó con Telésforo García, destacado intelectual santanderino con quien siguió una larga amistad, además de realizar actividades en conjunto con otros empresarios para la fundación de organismos en beneficio de la colectividad española. Colaboró además con los editores de El Pabellón Español (1883-1890), y a partir de julio de 1888, Fernando Luis J. de Elizalde fue nombrado director del periódico, cargo que ejerció hasta el 28 de febrero de 1889.

Después de esta experiencia, J. de Elizalde fundó el periódico El Correo Español; el 9 noviembre de 1889 se publicó su primer número. Retomó el lema de El Pabellón Español ${ }^{10}$ para definir su cometido principal de El Correo Español, con una mínima variante: "diario dedicado a la defensa de los intereses españoles"11. Además, la práctica editorial de J. de Elizalde en EI

10 El diario El Pabellón Español dejó de publicarse a principios de 1890.

11 El término "defensa de los intereses" fue utilizado con frecuencia en el siglo XIX y principios del XX, para definir el enfoque de actividades de grupos 
Pabellón Español se vio reflejada en la hechura periodística de El Correo Español tanto en el enfoque político para el tratamiento de los noticas de España como en la estructura de las secciones del periódico, publicado en la misma imprenta, que J. de Elizalde compró a sus editores.

La continuidad del uso de la frase "defensa de los intereses de los españoles" como lema de algunos diarios españolistas, tiene su origen en la condecoración Real y Americana Orden de Isabel la Católica, creada por Fernando VII en 1815, con la finalidad de recompensar la lealtad y patriotismo, de la milicia y ciudadanos que se mostraran a favor de la defensa y conservación de los intereses de los españoles en España, América y Filipinas. En 1889, la orden dejó de denominarse Americana y su título quedó como Real Orden de Isabel La Católica ${ }^{12}$.

El diario que fundó J. de Elizalde, El Correo Español se publicó de 1889 a 1914 y tiene una correspondencia únicamente nominativa con el nombre del diario El Correo Español, que se inició en Argentina diecisiete años antes y que se publicó de 1872 a 1905. Ese diario fue fundado por Enrique Romero Jiménez y llevaba el lema "Diario político y de noticias, mercantil, industrial y anuncios". El lema se redujo en la década de 1890 a "Diario de la mañana"; entre sus directores destacan los periodistas Justo López de Gomara, Rafael Calzada y Fernando López Benedito (GARABEDIAN; SZIR; LIDA, 2009). Los enfoques de los diarios con el nombre El Correo Español, publicados en Argentina y México, aunque llevasen el mismo nombre y fuesen españolistas, eran independientes; aunque en algunas ocasiones hubo intercambio de reseñas o notas periodísticas entre ellos, sin equiparar sus enfoques. En España, en Madrid, también se

organizados; en este caso, tratándose de la situación política que vivía España con la pérdida de sus colonias en América desde principios del siglo XIX.

12 En febrero de 1889, durante su cargo de director del periódico El Pabellón Español (1888-1889), Luis J. de Elizalde recibió la Gran Cruz de Isabel La Católica, distinción al mérito civil, otorgada por su trabajo editorial en ese diario y su actividad en la gestión colectiva en la fundación de instituciones para beneficio de los españoles. 
publicó un diario con el nombre El Correo Español de 1888 a 1921 y llevaba el lema "Diario tradicionalista de la mañana", periódico carlista fundado por el periodista Luis María de Llauder.

Durante diez años, del 9 de noviembre de 1889 al 31 de mayo de 1898, J. de Elizalde, fue el editor de El Correo Español; después vendió el diario a otros editores españoles también integrantes de la Junta del Casino Español, hasta su cierre en diciembre de 1914.

Las demás incursiones de J. de Elizalde en los diarios españoles en México son meritorias. Paralelamente a la dirección de El Correo Español, impulsó la creación de otro diario españolista, La Nación, fundado en mayo de 1894 y publicado brevemente durante seis meses; también fue parte de los editores fundadores del diario La Iberia, en 1906, durante su etapa inicial.

\section{Contenidos en El Correo Español}

La revisión de los contenidos del diario El Correo Español, que inició su edición el 9 de noviembre de 1889, con tiradas irregulares el primer año, y a partir de junio de 1890 se convirtió en una publicación diaria, ha permitido rescatar valiosos documentos de la política peninsular, su relación con la política mexicana del periodo, noticias de las sociedades que se desarrollaban para beneficio de los españoles residentes en México; revisar las secciones para difundir las letras de escritores españoles y mexicanos, principalmente; y la naciente publicidad de negocios, de productos españoles y servicios nacionales, dirigidos principalmente a la colonia española en el país.

En el primer número, en las páginas 11 y 12, el fundador del diario, presentó la estructura del programa de trabajo. De esta manera, se definieron los objetivos periodísticos que permitieron el inicio y la eventual consolidación del diario, como medio informativo, con una propuesta que seguía la práctica periodística española.

El director de El Correo Español se benefició con la colaboración del destacado intelectual, escritor y empresario español, Telésforo García (1844-1918), para conformar la sección 
editorial del diario. Pablo Mora describe el trabajo de García: "representa la retroalimentación de un discurso hispanista suscrito a una tradición de periodistas y editores españoles que abogaron por la reivindicación de España en México" (MORA, 2008, p. 123).

Las secciones del diario establecidas en el prospecto original fueron fijas durante los primeros tres años de su edición. A partir de 1893 los nombres y el grafismo de algunas secciones se modificaron, quedando las principales: sección Editorial, sección de España, sección de Telegramas, integrando las noticias sobre México directamente en el diario, sin estar reseñadas en una sección particular, sino presentadas, en la primera página, con títulos cortos y precisos. Sumo a esta revisión el espacio privilegiado que tuvo la literatura-poesía, relatos cortos, cuento, novelas de folletín y reseñas literarias- en las páginas del diario, con varias entregas por número, tanto de autores españoles y mexicanos, convirtiéndose así en un portador de las letras de ambos países.

La sección literaria se presentó sin encabezado y los contenidos de prosa y lírica se presentaban en la primera y en la segunda páginas del diario, entre las notas periodísticas, y ocasionalmente, en algunos números aparecía el título Literatura. Se definieron otras secciones con titulares con clichés tipográficos: Acuarelas de la Semana, Croniquillas, Palos y Carambolas, Santoral, Comercio, Bolsa, entre otros, referentes a breves reseñas de acontecimientos que interesaban a los habituales lectores del diario, y que por lo general se presentaban en la segunda y tercera página del diario; la página cuatro del diario se dedicó principalmente a la divulgación de anuncios publicitarios.

El Correo Español buscó ampliar sus contenidos para llegar a un número mayor de lectores primordialmente a españoles residentes en México y a los interesados en sus empresas y negocios. La aceptación del diario en la sociedad española radicada en México permitió la reducción de su precio y para asegurar un número mayor de lectores se presentó el servicio de suscripciones semestrales.

El prospecto de este diario españolista se mantuvo igual durante los primeros años de su publicación, con variaciones en la presentación de la información a partir de los directores invitados 
a dirigir sus páginas; de esta manera se consolidó la divulgación de la información empresarial y cultural española en el país. Los cambios en la presentación de la información, durante los tres últimos años de la edición dirigida por su fundador, hasta 1898, se relacionan con el contexto español finisecular que resaltaban el esfuerzo político, económico, militar y el patriotismo español para conservar sus colonias en América, contextos evidentes en ensayos de opinión sobre la guerra hispano-estadounidense que culminó con el desastre del 98.

\section{Conclusiones}

De los españoles radicados en México, sobresalen las redes promovidas por Telésforo García, quien reunió a editores y periodistas, de las que fue favorecido J. de Elizalde en su práctica editorial. Durante los dos primeros años de la edición de El Correo Español contó el apoyo de españoles radicados en México, los industriales, Pedro Peláez y Delfín Sánchez, y con las entregas de los escritores, Josefa Pujol de Collado, José María Bermejillo, Casimiro del Collado (El Correo Español. Año III, México, sábado 9 de noviembre de 1891, p. 10)

A estos se sumaron posteriormente los jefes de redacción y colaboradores con artículos y reseñas: Francisco Romero, Alberto Araus, Francisco Durante, por nombrar a los siempre presentes, en diferentes etapas, en esta primera década de edición del diario, además de los mexicanos Félix María Alcérreca y Agustín Alfredo Núñez; sumo el fraternal compañerismo con periodistas y editores en otros diarios que se publicaban paralelamente a El Correo Español. Estas relaciones revelan las redes de trabajo existentes entre escritores y periodistas, españoles y mexicanos, que en ocasiones publicaban o pasaban de un periódico a otro, en ese activo periodismo de fin de siglo.

En las páginas de ese medio impreso se reflejaron los intereses empresariales y culturales, además del sentir nacionalista de los españoles emigrados; en artículos de opinión, 
avisos y noticias se narraron las actividades que realizaban los españoles, empresarios, administrativos y miembros de las instituciones que se asociaron para cuidar sus intereses en México, a través de la Cámara de Comercio Española, El Casino Español, la Junta Patriótica y las sociedades de Beneficencia Española. Estos motivos fueron la continuidad de los apartados publicados inicialmente en el bisemanario político El Centinela Español (1879-1883), en el diario El Pabellón Español (18831889) y que El Correo Español prosiguió en "la defensa de los intereses de los españoles en México" tal como manifestaba el lema del periódico.

De manera que este ensayo presenta una revisión del contexto de la prensa periódica española; se centra en la migración de editores y escritores; en el aporte españolista a la difusión de noticias, ensayos políticos y sociales con la relevancia de la circulación de la literatura a través de los diarios que fundaron en México, elementos que permiten conocer e interpretar su contribución al periodismo finisecular.

\section{Bibliografía}

CLARK DE LARA, Belem; FLORES MONROY, Mariana. Estudio introductorio. En: El Renacimiento periódico literario, segunda época. Edición facsimilar. México: Universidad Nacional Autónoma de México, Coordinación de Humanidades, 2006. p. VIII.

ELIZALDE, Lydia. Fernando Luis J. de Elizalde, editor fundador de El Correo Español. En: GARRITZ, Amaya (Coordinadora). Aportaciones e integración de los vascos a la sociedad mexicana en los siglo XIXXXI. México: Universidad Nacional Autónoma de México, Instituto de Investigaciones Históricas, Centro Vasco Euskal Etxea, Ministerio de Cultura del Gobierno Vasco, 2008. p. 359-369.

GARABEDIAN, Marcelo; SZIR, Sandra; LIDA, Miranda. Prensa argentina siglo XIX. Imágenes, textos y contextos. Buenos Aires: Ediciones de la Biblioteca Nacional; Teseo, 2009. 
GRANADOS, Aimer. Debates sobre España. El hispanoamericanismo en México a fines del siglo XIX. México: El Colegio de México, Universidad Autónoma Metropolitana-Cuajimalpa, 2010. Colección "Ambas orillas".

LIDA, Clara E. La inmigración española en México: un modelo cualitativo. En: CHÁVEZ, Alicia Hernández; MIÑO GRIJALBA, Manuel (Coords). Cincuenta años de historia de México. México: El Colegio de México, 1993. v. 1, p. 201-215.

LIDA, Clara E. Los españoles en el México independiente: 1821- 1950. Un estado de la cuestión. Historia Mexicana, v. LVI, n. 2, p. 613-650, 2006.

MARTÍNEZ MARTÍN, Jesús A. (Dir.). Historia de la edición en España 1836-1936. Madrid: Marcial Pons Historia, 2001.

MORA, Pablo; MIQUEL, Ángel (Comps. y eds.). Españoles en el periodismo mexicano. Siglos XIX y XX. México: UNAM, Instituto de Investigaciones Bibliográficas; UAEM, Fundación Carolina, 2008.

MORA, Pablo. Telesforo García, articulista y polemista en el Centinela Español. En: MORA, Pablo; MIQUEL, Ángel (Comps. y eds.). Españoles en el periodismo mexicano. Siglos XIX y XX. México: UNAM, Instituto de Investigaciones Bibliográficas; UAEM, Fundación Carolina, 2008. p. 123-136.

MORA, Pablo. Presentación. En: MORA, Pablo; MIQUEL, Ángel (Comps. y eds.). Españoles en el periodismo mexicano. Siglos XIX y XX. México: UNAM, Instituto de Investigaciones Bibliográficas; UAEM, Fundación Carolina, 2008. p. 15-20.

PI-SUÑER LLORENS, Antonia. "Hay que confesarlo: el imperio tiene su estrella". Anselmo de la Portilla y la Razón de México (1864-1865). En: MORA, Pablo; MIQUEL, Ángel (Comps. y eds.). Españoles en el periodismo mexicano. Siglos XIX y XX. México: UNAM, Instituto de Investigaciones Bibliográficas; UAEM, Fundación Carolina, 2008. p. 65-76. 
RUIZ CASTAÑEDA, María del Carmen. La prensa durante el Porfiriato. In: RUIZ CASTAÑEDA, María Del Carmen; REED TORRES, Luis; CORDERO Y TORRES, Enrique. En: . El periodismo en México. 450 años de historia. Prólogo de Salvador Novo. 2 ed. México: UNAM, Escuela Nacional de Estudios profesionales Acatlán,1980. p. 229-262.

RUIZ CASTAÑEDA, María del Carmen. El Mosaico Mexicano, o colección de amenidades curiosas e instructivas. En: DE LA TORRE, Laura Suárez (Ed.). Empresa y cultura en tinta y papel (1800-1860). México: UNAM, Instituto de Investigación Dr. José María Luis Mora, 2001. p. 529-535.

SÁNCHEZ ILLÁN, Juan Carlos. La edición de periódicos y la empresa periodística. En: MARTÍNEZ MARTíN, Jesús A. (Dir.). Historia de la edición en España (1836-1936). Madrid: Marcial Pons Historia, 2001. p. 397-416.

SPECKMAN GUERRA, Elisa. EI Porfiriato. En: Nueva historia mínima de México. El Porfiriato. México: El Colegio de México, 2013. p. $192-225$.

VIEYRA SÁNCHEZ, Lilia. La sociedad de Beneficencia Española a través del periódico La Colonia Española (1873-1879). En: CANO ANDALUZ, Aurora; SUÁREZ CORTINA, Manuel; TREJO ESTRADA, Evelia (Ed). Cultura liberal, México y España: 1860-1930. Santander: Publican Ediciones, Universidad de Cantabria; México D.F.: UNAM, Instituto de Investigaciones Históricas; UNAM, Instituto de Investigaciones Bibliográficas, 2010. p. 465-489. 


\section{Internet}

ANDRIES, Lise. Transferencias culturales en la prensa y los impresos entre Francia y México en el siglo XIX, Bulletin hispanique [En ligne], v. 113, n. 1, p. 457-467, 2011. Mis en ligne le 01 juin 2014. Artículo disponible en: <http://bulletinhispanique.revues.org/1554>. Consulté le 10 janvier 2016.

BUCHENAU, Jürgen. Inversión extranjera y nacionalismo: lo paradójico de la política internacional de Porfirio Díaz, Dimensión Antropológica, México D.F., v. 6, p. 7-24, enero-abr., 1996. Artículo disponible en: <http:// www.dimensionantropologica.inah.gob. $m x / ? p=1475>$.

COUDART, Laurence. Periódicos franceses de la Ciudad de México: 1837-1911. En: PÉREZ SILLER, Javier (Coord.). México-Francia. Memoria de una sensibilidad común. Siglos XIX-XX. México: BUAP; El Colegio de San Luis; CEMCA, 1998. p. 103-141. Artículo disponible en:< http://books.openedition.org/cemca/2773>.

LEDEZMA MARTÍNEZ, Juan Manuel. Telesforo García: un emigrante montañés en el Porfiriato. In: CAIRO CAROU, Heriberto; CABEZAS GONZÁLEZ, Almudena; MALLO GUTIÉRREZ, Tomás; CAMPO GARCÍA, Esther del; CARPIO MARTIN, José (Eds). XV Encuentro de Latinoamericanistas Españoles, 2012. Madrid, España: Trama editorial; CEEIB, 2013. p. 990-1000. Artículo disponible en: <https://halshs. archives-ouvertes.fr/halshs-00876191>.

PICCATO, Pablo. Altibajos de la esfera pública en México de la dictadura republicana a la democracia corporativa. La era de la prensa. Artículo disponible en: <http://www.columbia.edu/ pp143/10PabloPiccato.pdf>.

THÉRENTY, Marie-Eve. Entrevista de Jaimeduardo García. El siglo XIX, inicio de la era mediática. La Jornada Semanal, n. 882, 29 enero 2012. Artículo disponible en: <http://www.jornada.unam.mx/2012/01/29/ sem-jaime.html>. 
VIEYRA SÁNCHEZ, Lilia. La relación de los empresarios peninsulares con México a través de El Correo Español. En: SEMINARIO INTERDISCIPLINARIO DE ESTUDIOS COMPARADOS, 7., 2014, Pachuca de Soto. Cultura liberal México y España en el periodo de entre siglos. Disponible en: <http://www.h-mexico.unam.mx/node/14862>.

\section{Hemerografía}

EL CORREO ESPAÑOL. México. Año III, p. 10, sábado 9 de noviembre de 1891.

Recebido em julho de 2016. Aprovado em janeiro de 2017. 